\title{
Barriers and attitudes towards HIV Voluntary Counselling and Testing (VCT) among Secondary School Pupils of Sengerema in Mwanza
}

\author{
By Omary Sukari MD5 2007/08
}

\begin{abstract}
:
OBJECTIVE:

To determine barriers and attitudes towards voluntary counseling and HIV-testing among secondary school students in Sengerema district.
\end{abstract}

\section{METHODOLOGY:}

A cross-sectional study was done in Sengerema district, Mwanza August 2006. A total of 400 secondary school students from the two schools Sengerema district, Mwanza from August to September 2006 were included in the study. By using simple random sampling technique, two secondary schools (Sima and Tuitange) were selected and enrolled in the study.

After a verbal consent from each interviewee as well as observing confidentiality to the information data was collected using a pre tested Swahili questionnaire. Data analysis was done using EPI INFO 2002.

\section{RESULTS:}

A total of 400 students from the two secondary schools were interviewed. Out of the 400 students $54 \%$ were females. The majority (95.8\%) of these students knew that VCT is necessary and a large number (33.8\%) of them gave a reason to get HIV education as a reason for HIV services.

Only a small number (4.2\%) of the students thought that VCT is not necessary with (47.8\%) said it to be against the religious teachings. A large proportion (65.8\%) of the students knew VCT sites in Sengerema district but only a few (24.3\%) of them ever used available VCT services. Of those who ever used VCT services $32.7 \%$ were just interested in knowing their HIV status and to get HIV education and only a small number (6.2\%) of students used VCT services because they were pressurized by their spouses.

For those who never used VCT services (41.8\%) said they feared being labeled as HIV positive and 34.9\% said these services were not meant for students. It was also observed in this study that VCT services were more accepted among female students than male students.

\section{CONCLUSION:}

From the findings it is concluded that a large number of students knew thatVCT use is necessary and the acceptance of VCT among the students is influenced by age where younger students were more willing to use VCT services than older students.

The use of VCT services is positively correlated with the level of education and that though a large number of students knew that VCT services are necessary only a small number of students use VCT services. It is recommended that much more effort should be emphasized on encouraging young people to use VCT services.

\section{INTRODUCTION}

Voluntary Counselling and Testing plays a critical role in HIV prevention, early diagnosis of HIV infection as well as timely therapeutic or prophylactic interventions1. HIV testing and counseling has further been shown to promote risk reduction in certain groups, behaviour change and reduced transmission². Young people are the most vulnerable and the most affected section of the global population.
It is estimated that at least more than half of all HIV infections (almost 7,000 daily) worldwide occur among young people aged between 15 and 24 years $^{3}$. The situation is especially serious in developing countries where young people form a significant proportion and where the HIV epidemic has been most severe ${ }^{3}$. With young people at the centre of the epidemic, it is important to understand the extent to which they are willing 
to test for HIV infection and the factors associated with such willingness.

In Tanzania, VCT plays a key part in HIV-related prevention and care. It has been shown to be effective in influencing change in sexual behaviour and practices (National guidelines for the clinical management of HIV/AIDS. The goals of public health policy regarding HIV VCT are to diagnose HIV infection for timely therapeutic or prophylactic interventionsand secondly to identify unrecognized infections so that behavior associated with viral transmission can be modified. Understanding factors affecting the use of VCT services and the acceptability of HIV testing is essential to success of HIV prevention and VCT programs.

The information obtained from this study might be a useful means to find ways to encouraged young people to test for HIV as this is the most important option that may provide useful information for HIV prevention and also encouraging behavioral changes among youths especially those in secondary schools.

\section{METHODOLOGY}

This was a cross-sectional community based study involving secondary school pupils of Sengerema district in Mwanza region. The study involved 400 pupils who were obtained using multi-stage sampling at school level from the number of selected wards in Sengerema district. Thereafter simple random sampling was the technique used to obtain the representative number of pupils. Selfadministered questionnaires were administered to this representative sample of pupils. Data were coded into the computer and cleaned for errors. Data analysis was done using Epi-info computer program version 3.3.2. Ethical clearance for this study was granted by the MUHAS Research \& publication committee and permission to conduct the study locally was sought from headmasters of the respective schools. Anonymity and confidentiality was maintained throughout the study.

\section{RESULTS}

A total of 400 students from two secondary schools were interviewed. Out of the 400 students 54\% were females.
Table 1: REASONS GIVEN BY STUDENTS TO WHY VCT IS NECESSARY

\begin{tabular}{|l|c|c|}
\hline REASONS & $\begin{array}{c}\text { NUMBER } \\
\text { OF } \\
\text { STUDENTS }\end{array}$ & PERCENTAGE \\
\hline Check HIV status & 226 & 30.5 \\
\hline $\begin{array}{l}\text { To receive } \\
\text { HIV/AIDS } \\
\text { education }\end{array}$ & 250 & \\
\hline $\begin{array}{l}\text { To receive } \\
\text { advises if } \\
\text { HIV positive }\end{array}$ & 248 & 33.8 \\
\hline Others & 14 & 33.5 \\
\hline I don't know & 2 & 1.9 \\
\hline Total & 740 & 0.3 \\
\hline
\end{tabular}

Others = pregnant, married

Most students (95.8\%) knew that VCT is necessary. A higher proportion of students thought that VCT was necessary in order to get HIV/AIDS education and a small proportion $(1.9 \%)$ of students thought that it helps to change youth's behaviour.

TABLE 2: REASONS GIVEN BY THE STUDENTS TO WHY VCT IS NOT NECESSARY

\begin{tabular}{|l|c|c|}
\hline REASONS & $\begin{array}{c}\text { NUMBER } \\
\text { OF } \\
\text { STUDENTS }\end{array}$ & PERCENTAGE \\
\hline $\begin{array}{l}\text { It misleads } \\
\text { the society }\end{array}$ & 10 & 43.5 \\
\hline $\begin{array}{l}\text { It is against the } \\
\text { religious teachings }\end{array}$ & 11 & 47.8 \\
\hline Others & 2 & 8.7 \\
\hline Total & 23 & 100.0 \\
\hline
\end{tabular}

A large number (47.8\%) of students who thought VCT was not necessary said it is against religious teachings and some said it misleads the society.

\section{TABLE 3: FACTORS WHICH PROMOTE VCT} ATTENDANCES

\begin{tabular}{|l|c|c|}
\hline FACTORS & NUMBER & PERCENTAGE \\
\hline $\begin{array}{l}\text { To know HIV status } \\
\text { To receive }\end{array}$ & 72 & 28.0 \\
\hline $\begin{array}{l}\text { HIV/AIDS } \\
\text { education }\end{array}$ & 84 & 32.7 \\
\hline $\begin{array}{l}\text { Pressurized by } \\
\text { a boyfriend/girlfriend }\end{array}$ & 16 & 6.2 \\
\hline
\end{tabular}

Among the factors promoting the use of VCT services, getting HIV/AIDS education was highly mentioned. Pressure from boyfriends/girlfriends was the least 
TABLE 4: FACTORS WHICH HINDER VCT ATTENDANCE

\begin{tabular}{|l|c|c|}
\hline FACTORS & NUMBER & PERCENTAGE \\
\hline $\begin{array}{l}\text { VCT centres are located } \\
\text { very far away }\end{array}$ & 44 & 16.9 \\
\hline $\begin{array}{l}\text { Fear of being } \\
\text { labelled as HIV positive }\end{array}$ & 109 & 41.8 \\
\hline $\begin{array}{l}\text { They are not meant } \\
\text { for students }\end{array}$ & 91 & 34.9 \\
\hline Fear of teachers & 13 & 5.0 \\
\hline Others & 4 & 1.4 \\
\hline Total & 261 & 100.0 \\
\hline
\end{tabular}

A large number $(47.8 \%)$ of students who thought VCT was not necessary said it is against religious teachings and some said it misleads the society.

\section{TABLE 5: SUGGESTIONS OF PLACES FOR VCT PROVISION GIVEN BY STUDENTS}

\begin{tabular}{|l|c|c|}
\hline REASONS & $\begin{array}{c}\text { NUMBER } \\
\text { OF } \\
\text { STUDENTS }\end{array}$ & PERCENTAGE \\
\hline Hospitals & 369 & 43.5 \\
Private clinics & 219 & 25.8 \\
\hline Polyclinics & 137 & 16.1 \\
Others & 124 & 14.6 \\
\hline Total & 849 & 100.0 \\
\hline
\end{tabular}

A large proportional (43.5\%) of the respondents suggested VCT services to be provided in hospitals, and small proportion $(14.6 \%)$ proposed that VCT services should be available in other places such as in schools and also any other place easily reachable.

\section{DISCUSSION}

The role of VCT is to provide counselling services to individuals who wish to know health status in this era of HIV/AIDS. VCT has been found to be the most important approach towards the control of HIV/ AIDS as it is the entry point to the management of AIDS and AIDS related diseases and in prevention of the disease. Several studies have been done to identify the factors influencing people's willingness to test for HIV among various population groups.

The present study revealed that 24.2\% of respondents had accessed VCT services. These findings differ from those of a study done in Botswana among secondary and tertiary students ${ }^{4}$ which found that just over half of the students were willing to test for HIV infections. It was also revealed that of the $24 \%$ who used VCT service
$56 \%$ of them were below the age of 18 and only $44 \%$ were above 18. In general the willingness to use VCT services was shown to decrease with the increase in age.

This may be due to the fact that as the age increases the students becomes more sexually active and so less willing to test for HIV. Similar findings were seen in a study done among students in Botswana which revealed that in both secondary and tertiary institutions, younger students were more likely to test than older students. Testing rates have been shown to decrease by $2.5 \%$ with each yearly increase in age ${ }^{1}$ suggesting that as young people in school grow older and reach higher levels of education, they are more likely to become sexually active and less willing to test for HIV.

From this study only $24.2 \%$ of youth were found to be using VCT services and $75.8 \%$ were not using. These findings are different from experience in other sub Saharan African countries that shows that youth actively seek and receive VCT services.

A number of reasons were given by those students who were not using VCT services, about $41.8 \%$ said they fear being labelled HIV positive. Also a large proportion of students 34.9\% said that VCT services were not meant for students.

Some students (16.9\%) said that VCT centres are located very far away from their school. A small proportion (1.4\%) had other reasons for example not having decided yet, limited time and a belief of not being infected. Similar reasons for failing to use VCT were given by students in one study done among students in South Africa ${ }^{2}$. This implies that a large number of youths in this country are not yet well educated on the use of VCT and its benefits.

When trying to establish gender differences on attitudes and practices of VCT among youth, this study revealed that among youth using VCT services in Sengerema, the majority (52.6\%) are females and minority (47.4\%) are males. Similar findings were seen in a study done in Philadelphia where it was shown that there are gender-based similarities and differences in the correlates of testing ${ }^{5}$. 
Attitudes and practices towards HIV testing among young people can be influenced by availability and accessibility of VCT centers. From this study 263(65.8\%) of the study population out of 400 knew about the location of the VCT centres in Sengerema and $34.2 \%$ did not know. A large number of students (54.2\%) knew all the five VCT centers available in Sengerema town and 32\% knew $<2$ centres. This implies that in spite the awareness of the VCT services in a particular area, the use of these services may be influenced by other factors such as the number of VCT centers in that area.

Location of VCT services may be among the factors that cause low turnout among youth. In this study when young people were asked to give suggestions of places where they would like VCT services to be provided the majority (43.5\%) preferred hospitals and other places like schools and places where many youth are found especially those who have no access to school will be suitable and $25.8 \%$ said polyclinics are preferable.

\section{CONCLUSION}

This study shows that majority of the secondary school students know that VCT is necessary with the major reason of getting HIV/AIDS education. The willingness towards VCT use was found to have been influenced by age of the students where younger students were more willing to use VCT services than older students. Furthermore, it was shown that willingness to use VCT services increases with increase in the level of education.

\section{RECOMMENDATIONS}

The role of media should further be emphasized, as it appears that students get most of the information about HIV/AIDS and VCT through media such as magazines, radio, and television.

Number of VCT centers should be increased in Sengerema district so that these services should be more available to the students and the general population at large since there are only 8 VCT centers serving a population of 550,000.

\section{REFERENCES}

1. Gage, A.J., Ali, D. Factors associated with self-reported HIV testing among men in Uganda. AIDS Care, 2004, 17(2), 153- 65.

2. Peltzer, K., Nzewi, E., Mohan, K. Attitudes towards HIVantibody testing and people with AIDS among university students in India, South Africa and United States. Indian Journal of Medical Sciences, 2005, 58(3), 95-108.

3. Shuter, J.,Alpert, P.L.,M.G., Greenberg, B., Klein. Rates of and factors associated with self reported prior HIV testing among adult medical patients in an inner city emergency department in the Bronx, New York City. Journal of Acquired Immune Deficiency Syndromes and Retrovirology, 14, 61-/6. UNAIDS, 2004.

4. Bond, L,.Lauby, J., Batson, H. HIV testing and the role of individual- and structural-level barriers and facilitators. AIDS Care, 2004, 17(2),

125-/40.

5. Ransom, J.E., Siler, B., Peters, R., Maurer, M.J. Worry: women's experience of HIV testing. Qualitative Health Research, 2004, 15(3), 382-93. 